\title{
Tiempo para la vida. El concepto de libertad en José Mujica
}

\author{
Time for life. The concept of freedom in José Mujica
}

Gerardo Albistur*

Resumen: El presente artículo repasa dos discursos paradigmáticos de José Mujica, presidente del Uruguay entre 2010 y 2014. Se analiza de qué manera esta construcción discursiva distingue la libertad en el plano político de la libertad de mercado, para establecer una relación entre las concepciones de izquierda y los elementos distintivos de la liberad individual. Separados de las concepciones republicanas, estos componentes del pensamiento liberal en el discurso de Mujica, justifican la hipótesis del éxito de una aproximación al liberalismo político en el pensamiento de la izquierda, con sustento en el pragmatismo de la acción.

Palabras clave: Mujica, liberalismo, libertad, izquierda, republicanismo, Uruguay

\begin{abstract}
This article reviews two paradigmatic speeches from the former Uruguayan president José Mujica (2010-2014). In order to show the relationship between Left-wing conceptions and the distinctive elements of individual freedom, this articles analyzes how his discourse distinguish freedom in the political field from freedom of markets. These liberal components in Mujica's speeches, separated from republicanist conceptions, support the hypothesis of an approximation of the Left-Wing ideas to political liberalism, supported by the pragmatism of action.
\end{abstract}

Keywords: Mujica, liberalism, freedom, left-wing, republicanism, Uruguay

Recibido: 24 mayo 2017

Aceptado: 3 septiembre 2017

\footnotetext{
* Uruguayo. Doctor en Ciencias Sociales (Facultad de Ciencias Sociales - Universidad de Buenos Aires). Magíster en Ciencia Política (Facultad de Ciencias Sociales - Universidad de la República). Licenciado en Ciencias de la Comunicación (Universidad de la República). Docente del Departamento de Ciencias Humanas y Sociales. Instituto de Comunicación. Facultad de Información y Comunicación. Universidad de la República. Montevideo - Uruguay. gerardo.albistur@ fic.edu.uy
} 


\section{Introducción}

El ex presidente de Uruguay, José Mujica, es una celebridad mundial. La evidencia es tan axiomática como categórica: la popularidad de "Pepe" Mujica no decayó siquiera mínimamente luego de finalizado su mandato presidencial (2010-2014). Una revisión exhaustiva de los sucesos que lo demuestran sería excesivamente extensa, en la medida que cada día se suman episodios que comprueban esta afirmación. Basta decir que desde Berlín a Estambul, ${ }^{1}$ desde el New York Times a la Radiotelevisión Española, ${ }^{2}$ la presencia del "presidente más pobre del mundo"3 asegura una audiencia multitudinaria.

Por medio de entrevistas periodísticas en medios impresos, televisión, radio, libros, cine documental, y sobre todo a través de sus audiciones radiales, ha estrechado un vínculo permanente con una audiencia que superó las fronteras nacionales. Por este motivo su ideología política se encuentra dispersa en una infinidad de discursos formulados públicamente o como resultado del diálogo con entrevistadores y difundidos a través de distintos soportes.

Exponente de las experiencias progresistas y de izquierda que en la última década se produjeron en la región, fue elegido presidente del Uruguay en 2009, luego de superar en segunda vuelta a Luis Alberto Lacalle, candidato del Partido Nacional y presidente uruguayo entre 1990 y 1995. Los adversarios en la contienda electoral no podían ser más antagónicos. La oposición entre Lacalle, cuya candidatura "[...] tuvo cierto aire a restauración borbónica", ${ }^{4}$ y Mujica, un candidato que "[...] evoca las revoluciones plebeyas", 5 no dejó de despertar durante la campaña electoral fuertes dudas sobre la

\footnotetext{
${ }^{1}$ En junio de 2016, Mujica visitó la capital alemana invitado por el Instituto Iberoamericano de Berlín, para celebrar los 160 años de las relaciones bilaterales entre Uruguay y Alemania. El diario El Observador de Montevideo, comentaba en los siguientes términos la llegada de Mujica a la conferencia: "La camioneta no podía avanzar. La muchedumbre encerró al vehículo para tomarse selfies, dialogar con su ocupante y hasta golpear suavemente los vidrios negros para recibir una respuesta del afamado personaje". El Observador: "Mujica en Berlín, entre selfies, aplausos y nada de protocolo", 26/06/2016. Recuperado de http://www.elobservador.com.uy/mujica-berlin-selfies-aplausos-y-nada-protocolo-n932292.

Durante su visita a Estambul en noviembre de 2015, Sputnik Mundo informaba de la siguiente manera: "«Mujica super star» llena estadios, despierta elogios, provoca emociones [...]". Sputnik Mundo: "El ex presidente uruguayo José Mujica se ha convertido en un embajador voluntario de su país en el mundo", 03/11/2015. Recuperado de https://mundo.sputniknews.com/americalatina/201511031053248932-uruguaymujica-embajador-voluntario-mundo/.

${ }^{2}$ El New York Times llamó la atención en 2013 sobre la personalidad de Mujica en la portada, algo inédito para un presidente uruguayo. New York Times: “After Years in Solitary, an Austere Life as Uruguay's President", 05/01/2013. Recuperado de http://www.nytimes.com/2013/01/05/world/americas/after-years-insolitary-an-austere-life-as-uruguays-president.html.

En octubre de 2014, RTVE emitió un extenso reportaje a Mujica al finalizar su mandato presidencial. "Mujica o simplemente 'El Pepe"', 29/09/2014. Recuperado de http://www.rtve.es/television/enportada/reportajes/americas/pepe-mujica/.

${ }^{3}$ La British Broadcasting Corporation (BBC) lo consideró en un artículo publicado en noviembre de 2012, "el presidente más pobre del mundo", afirmación que fue utilizada ampliamente por los medios de comunicación internacionales. BBC News: "Jose Mujica: The world's 'poorest' president", 15/11/2012. Recuperado de http://www.bbc.com/news/magazine-20243493.

${ }^{4}$ Adolfo Garcé, "Uruguay 2009: de Tabaré Vázquez a José Mujica", Revista de Ciencia Política, vol. 30 , núm. 2, Pontificia Universidad Católica de Chile, Santiago, 2010, 509.

${ }^{5}$ Idem.
} 
reacción del electorado uruguayo. Sin embargo, José Raúl Rodríguez y Daniela Vairo concluyen que el triunfo de Mujica en las elecciones nacionales se debe a que su postulación fue lo suficientemente atractiva como para determinar el resultado. Variables de largo plazo como la progresiva transformación del sistema de partidos uruguayo, y de mediano plazo, especialmente la gestión exitosa del primer gobierno del Frente Amplio (2005-2009), completan la explicación de su triunfo pero la oferta electoral, o sea, el propio Mujica, fue un factor decisivo pese a las dudas iniciales sobre su desempeño. ${ }^{6}$ No obstante, ninguno de estos elementos explica la dimensión internacional que adquirió. Semejante notoriedad, excepcional tratándose de un líder de la izquierda latinoamericana, no parece ser el resultado de las mismas condiciones internas del éxito electoral.

Durante el mandato presidencial de José Mujica, la aprobación de tres leyes fue suficiente para catapultar la idea, entre los propios liberales, del camino liberal que confirmaba el Uruguay. ${ }^{7}$ Fueron únicamente tres leyes, cuyo valor está más en la dirección de las libertades conquistadas que en su abundancia: la ley de interrupción voluntaria del embarazo que despenalizó el aborto, ${ }^{8}$ la ley de matrimonio igualitario que habilitó el casamiento entre personas del mismo sexo, ${ }^{9}$ y la ley que reguló la producción y el consumo de marihuana para fines recreativos. ${ }^{10}$ Solo esta última fue una iniciativa del Poder Ejecutivo encabezado por Mujica, que fundamentó su pertenencia más en la necesidad de un cambio en la política antidrogas, que en la ampliación de la esfera de la libertad para los consumidores de cannabis. La ley de matrimonio igualitario fue elaborada por el colectivo "Ovejas Negras", una organización de la sociedad civil para la defensa de los derechos de las personas LGTB, y suscrita por senadores del Frente Amplio pese a que la iniciativa no formaba parte del programa ni de la agenda del gobierno. También la ley que despenalizó el aborto fue presentada por legisladores del Frente Amplio, y en este caso las negociaciones políticas rebajaron el avance del proyecto original. ${ }^{11}$

Pese a la "amortiguación" que también significaron estas políticas respecto al ideal de cambio político y social, pese a esa característica, advertida por Real de Azúa, que “[...] en el Uruguay los conflictos sociales y políticos no llegan a la explosión, de que toda tensión se «compone» o «compromete», al final, en un acuerdo [...]", ${ }^{12}$ estas leyes fueron el resultado del ambiente favorable que el gobierno de Mujica dispensó a iniciativas tendientes a eliminar prohibiciones. En otras palabras, la "amortiguación", aquí, fue menos

\footnotetext{
${ }^{6}$ Rodríguez, Raúl; Vairo, Daniela, "Las claves del éxito de Mujica en las presidenciales uruguayas de 2009”. REVISTA DEBATES, Porto Alegre, v. 5, n. 2, 2011, p. 113.

${ }^{7}$ Así lo hizo saber la revista The Economist en diciembre de 2013, luego de la aprobación de normas en el Uruguay que consideró liberales, especialmente la regulación del cannabis psicoactivo por parte del Estado, y la legalización del matrimonio de personas del mismo sexo. The Economist: "Earth's got talent", 05/01/2013. Recuperado de http://www.economist.com/news/leaders/21591872-resilient-ireland-booming-south-sudantumultuous-turkey-our-country-year-earths-got.

${ }^{8}$ Ley 18.987, promulgada por el Poder Ejecutivo el 22 de octubre de 2012.

${ }^{9}$ Ley 19.075, promulgada por el Poder Ejecutivo el 03 de mayo de 2013.

${ }^{10}$ Ley 19.172, promulgada por el Poder Ejecutivo el 20 de diciembre de 2013.

${ }^{11}$ Niki Johnson; Diego Sempol, 2016. "Igualdad de género y derechos de la diversidad sexual: avances y rezagos en el gobierno de Mujica", Bentancur, Nicolás; Busquets, José, El decenio progresista. Las políticas públicas de Vázquez a Mujica, Montevideo, Fin de Siglo-Instituto de Ciencia Política, UdelaR, 2016, p. 162.

${ }^{12}$ Carlos Real de Azúa, Uruguay. ¿Una sociedad amortiguadora?, Montevideo, Ediciones de la Banda Oriental, 1984, p. 12.
} 
inmovilidad que "impulso" transformador. Por ese motivo, también, se trató de medidas polémicas, cuya discusión casi simultánea no es frecuente tanto en el ámbito local como internacional, poco inclinados a la consideración de iniciativas típicamente liberales. Estas lo fueron, en la medida que proponen un nuevo límite que amplía las libertades y reduce las restricciones, puesto que hay una raíz liberal en el sentido que Alfredo Cruz Prados le otorga a la relación entre la ley y la libertad: "La cuestión -típicamente liberal- que esta función plantea es cuál es el recorte mínimo imprescindible para dar protección legal a la libertad". 13

Pero el "liberalismo" de Mujica se expresó con mucha más elocuencia en su discurso. Desde esta premisa, el presente artículo se propone explorar una explicación sobre este fenómeno. Al contrario de lo que presenta como auto identificación ideológica, y al contrario también de los presupuestos históricamente construidos por las corrientes socialistas y de izquierda a las que el propio Mujica pertenece, se justificará la pertinencia de explicar la notable reputación del ex presidente uruguayo por su inclinación a las concepciones del liberalismo. Esta hipótesis no se apoya en los aspectos de la personalidad ni en la biografía de Mujica, sino en el pragmatismo y la ideología implícita de su discurso, al cual sus atributos personales en todo caso han contribuido a proporcionar verosimilitud y coherencia, así como las iniciativas aprobadas durante su gobierno, de clara dirección liberal.

Con este objetivo, en primer lugar se llamará la atención en torno a ciertos aspectos ideológicos a través del examen de dos discursos paradigmáticos de Mujica: el discurso pronunciado en la $68^{\circ}$ Asamblea General de Naciones Unidas el 24 de setiembre de $2013,{ }^{14}$ y la audición radial en su programa "Hablando al Sur" trasmitida por la emisora M24 de Montevideo el 17 de octubre de 2014, reproducida por la web de la Presidencia de la República; ${ }^{15}$ el primero de ellos se produjo en un ámbito de amplia visibilidad internacional, y el segundo fue la última audición que realizó antes de las elecciones nacionales de 2014. La elección de estas piezas discursivas responde a un doble criterio, de pertinencia dado que exponen los alcances de su concepto de libertad, y de enunciación puesto que se trata de discursos no mediados, es decir, fueron producidos sin otra intervención que la del propio enunciador. Ambas piezas, fueron discursos orales de los cuales es posible acceder a un registro sonoro. En tal sentido, son atribuibles al propio Mujica y solamente sobre él recae la responsabilidad del producto. Se trata de minimizar el problema planteado por Dominique Maingueneau, cuando advierte que "[...] las producciones verbales de la esfera mediática, mucho distan de acreditar la imagen que comúnmente uno se hace del autor como un individuo bien identificado que elabora un texto cuyo único responsable será él". ${ }^{16}$ No obstante, sin sumarlas como unidades de análisis, se recurrirá a otras fuentes, específicamente alguna de las innumerables entrevistas

\footnotetext{
${ }^{13}$ Cruz Prados, ob. cit. p. 94.

14 Naciones Unidas, Intervención de José Mujica en el Debate general de la Asamblea General de las Naciones Unidas, Reuniones del $68^{\circ}$ período de sesiones de la Asamblea General (2013-2014), Nueva York, 2013. Recuperado de https://gadebate.un.org/sites/default/files/gastatements/68/UY_es.pdf .

${ }^{15}$ Presidencia de la República, "Palabras del Presidente de la República, José Mujica, correspondientes al 17 de octubre de 2014". Recuperado de https://medios.presidencia.gub.uy/jm_portal/2014/noticias/NO O363/Desgrabacion_17102014.pdf, ${ }^{16}$ Dominique Maingueneau, Análisis de textos de comunicación, Buenos Aires, Nueva Visión, 2009, p. 157.
} 
periodísticas publicadas, con el objetivo de corroborar el criterio de pertinencia, aun cuando este material no cumpla con el criterio establecido de enunciación.

En segundo lugar, se repasará la distinción que corresponde a las tradiciones republicana y liberal, con especial énfasis en la construcción adversativa de la idea de libertad que elaboran, y sobre la que se asientan dichas tradiciones; para ello, se despejarán el liberalismo político y el liberalismo económico, como dos tradiciones separadas. En tercer lugar, se verificará en qué medida el discurso político de Mujica se adecua a la tradición liberal, pese a su propia reivindicación de la tradición republicana. Finalmente, se establecerá la relación entre liberalismo y socialismo, y en general el vínculo del liberalismo con las concepciones políticas de la izquierda. Se concluye con una discusión sobre las posibilidades que abre un discurso sobre la libertad que retoma una articulación poco frecuentada ente el liberalismo político, el anarquismo y el socialismo de la izquierda.

\section{Ideología, pragmatismo y discurso}

El pensamiento de José Mujica no puede adscribirse fácilmente en una corriente precisa. Sus fuentes y orígenes son diversos, como inusual ha sido su trayectoria política. Mujica nació en Montevideo en 1935. Inició la actividad política en la década del cincuenta acompañando al dirigente del Partido Nacional, Enrique Erro, que abandonó el nacionalismo en 1962 para fundar junto a socialistas como José Pedro Cardozo y Vivián Trías la Unión Popular, uno de los antecedentes del Frente Amplio. Integrante del Movimiento de Liberación Nacional (MLN-Tupamaros) en los años sesenta, preso político durante la dictadura cívico - militar (1973-1984), diputado del Frente Amplio en el período 1995-2000, senador a partir de 2001 y ministro del primer gobierno de Tabaré Vázquez (2005-2009), su peso en la política uruguaya fue acrecentándose hasta alcanzar la candidatura única a la presidencia por su partido, algo imprevisto pocos años atrás.

Quienes integraron el MLN-Tupamaros combinaron sin esfuerzo la diversidad ideológica con el pragmatismo de la acción. Como estableció Real de Azúa en 1971 cuando todavía operaban como una modalidad de "lucha con armas", ${ }^{17}$ los tupamaros provenían de las más variadas tradiciones políticas, "[...] de las disidencias a la línea oficial de los partidos comunista y socialista, del anarquismo, del trotskismo, del maoísmo, de los grupos católicos radicalizados [...]", y sin embargo, "el imperativo activista, pragmático parece haberse implantado en ellos como la fuerza y la urgencia de una auténtica vocación". ${ }^{18}$ A partir de entrevistas con varios miembros del movimiento armado, Clara Aldrighi también observa "[...] la ideología de la organización como una combinación de elementos dispares, una mezcla más que una conexión estructurada". ${ }^{19}$ Del mismo modo los documentos elaborados por el MLN exhibían este atributo, que según Adolfo Garcé se explica por el pragmatismo de la organización: "para los tupamaros no era posible

\footnotetext{
${ }^{17}$ Carlos Real de Azúa, Partidos, política y poder en el Uruguay (1971-Coyuntura y pronóstico), Montevideo, FHCE, Universidad de la República, 1988, p. 100.

${ }^{18}$ Idem, p. 94.

${ }^{19}$ Clara Aldrighi, Memorias de Insurgencia. Historias de vida y militancia en el MLN-Tupamaros. $1965-$ 1975, Montevideo, Ediciones de la Banda Oriental, 2009, p. 11.
} 
determinar a priori cuál es la teoría más correcta. Era necesario poner en práctica las concepciones existentes para ir construyendo, a partir de la práctica, la teoría revolucionaria". ${ }^{20}$

Conforme con estas características, el MLN-Tupamaros no fue exactamente $-\mathrm{O}$ simplemente- un movimiento de guerrilla urbana. Ante todo, se trató de un movimiento político, cuyas acciones armadas cumplían una función más política que militar. Para Francisco Panizza, “[...] a pesar de su énfasis en las acciones armadas, la lucha tupamara fue, en verdad, una de las más elaboradas estrategias de política simbólica en la historia uruguaya", ${ }^{21}$ o sea, un movimiento "[...] simultáneamente productor y actor de su propia narrativa"22, que priorizó la "propaganda armada" a través del relato de sus propias acciones. En este contexto, ideología y acción se conjugaban. Siguiendo este planteo, Garcé sostiene que "en el fondo, lo mejor que tuvieron como guerrilleros fue lo que tenían de políticos: picardía, intuición, capacidad de comunicación". 23

Particularmente Mujica, "[...] en quien se encarnan todos los aportes de los que se nutrieron conscientemente o no los tupamaros, reivindica también su herencia del anarquismo". ${ }^{24}$ Esta afirmación de Alain Labrousse se sustenta en las múltiples referencias de Mujica al anarquismo, pero también al socialismo, el republicanismo y el liberalismo, así como a la influencia de diversos personajes históricos que representan, también, enfoques ideológicos en alguna medida identificados. Los periodistas Andrés Danza y Ernesto Tulbovitz, confirman que "además de Rosa Luxemburgo y de Winston Churchill y de tanto otros a nivel internacional, exprimió a los caudillos históricos locales, como Luis Alberto de Herrera o José Batlle y Ordóñez. De todos ellos tomó herramientas para administrar mejor el Estado, aunque sin dejar de reivindicar el anarquismo". ${ }^{25}$

Pero en el discurso de Mujica, la idea anarquista de la libertad se realiza, en los hechos, en la libertad liberal, no en la libertad republicana del cuerpo político. Lo hace evidente cuando afirma que "la que respeta en serio la libertad es la anarquía," e inmediatamente matiza: "por eso, de todas las ideologías, es la que más me interesa. Pero la libertad humana no quiere decir la ausencia de responsabilidad ni la ausencia de límites". ${ }^{26}$ Esta es la razón por la cual para Mujica "el liberalismo y el anarquismo son primos hermanos", ${ }^{27}$ idea que sostiene cuando compara las reformas más notorias de su gobierno con las reformas liberales del batllismo de principios del siglo XX. Y en el plano de la

\footnotetext{
${ }^{20}$ Adolfo Garcé, 2011, "Ideologías políticas y adaptación partidaria: el caso del MLN-Tupamaros”, Revista de Ciencia Política, V. 31, N 1, Santiago, 2011, p. 121.

${ }^{21}$ Francisco Panizza, "Las políticas del signo. Los códigos y símbolos de la épica tupamara", Cuadernos del Claeh, No 10, Montevideo, 1985, p. 6.

${ }^{22}$ Idem, p. 7.

${ }^{23}$ Garcé, op. cit, p. p. 120.

${ }^{24}$ Alain Labrousse, Una historia de los tupamaros. De Sendic a Mujica, Montevideo, Fin de Siglo Editorial, 2011, p. 61.

${ }^{25}$ Andrés Danza, Ernesto Tulbovitz, Una oveja negra al poder. Confesiones e intimidades de Pepe Mujica, Montevideo, Sudamericana, 2017, p. 129.

${ }^{26}$ Ibid. p. 125.

27 Ibid. p. 133.
} 
acción política, "una virtud del político -subraya- es saber interpretar los tiempos y yo los interpreto con base en la libertad. Nosotros somos liberales en serio. ${ }^{28}$

En esta afirmación del liberalismo, se encuentra una de las definiciones más singulares de Mujica. Si bien son frecuentes en Mujica afirmaciones que refieren a la libertad republicana como libertad del cuerpo político en afinidad con los valores más arraigados de la izquierda identificada en los procesos de liberación nacional, la libertad que efectivamente reclama Mujica, y la que practica, es la libertad liberal, aunque el liberalismo no suele ser una tradición particularmente reconocida por la izquierda como fuente constitutiva de su identidad.

\section{El discurso sobre la libertad}

Mujica prácticamente no ha publicado textos escritos. El medio ha sido la palabra oral, y que la oralidad haya sido adecuada para una difusión amplia del mensaje no ha sido circunstancial. Para Philippe Breton "la palabra, sobre todo cuando es oral, cambia el mundo a su alrededor; es como una escritura sobre el otro, en el otro", ${ }^{29}$ lo que deja a la escritura del lado de la información y potencia a la oralidad como lo propio del vínculo comunicativo. Con este sentido, Mujica ha empleado casi exclusivamente el habla. Uno de los pocos textos escritos disponibles, publicado en su web oficial, ${ }^{30}$ es incluso una "carta" dirigida genéricamente al "pueblo", plena de marcas de oralidad.

El discurso frente a la Asamblea General de las Naciones Unidas es una de estas piezas discursivas cuyo texto se encuentra absolutamente subordinado a la expresión oral, y un buen ejemplo de lo que Ana Montero ha señalado como un discurso del que "[...] emerge un ethos sabio, reflexivo, viejo, superado, autocrítico y distante". ${ }^{31}$ En él, Mujica elabora una perspectiva ecologista, eminentemente pragmática, crítica de la etapa actual de desarrollo capitalista frente a la imposibilidad de un modelo de desarrollo sustentado en el consumo de masas.

La construcción de una idea de libertad está presente en toda la estructura discursiva: el actual modelo de desarrollo capitalista es incompatible con la libertad "[...] que supone Tiempo para vivir las relaciones humanas, amor, amistad, aventura, solidaridad, familia". ${ }^{32}$ Al modelo de desarrollo lo identifica como "civilización contra el tiempo libre que no paga y puede gozar escudriñando la naturaleza". ${ }^{33}$ En un sentido estricto, la libertad

\footnotetext{
28 Ibid. p. 225.

${ }^{29}$ Philippe Breton; David Le Breton, El silencio y la palabra contra los excesos de la comunicación, Nueva Visión, Buenos Aires, 2011, p. 58.

30 “Mensaje de José 'Pepe' Mujica | 27/02/2015”. El sitio web http://www.pepemujica.uy/, se inició en febrero de 2015, pocos días antes de que finalizara su mandato presidencial. Su antecedente más inmediato fue el sitio http://www.pepetalcuales.com.uy/, que dejó de actualizarse luego de la elección de 2009, pero solo dejó de estar activo a fines de 2014, después del segundo triunfo de Tabaré Vázquez en las elecciones nacionales.

${ }^{31}$ Ana Soledad Montero, "El joven militante y el viejo sabio. Relatos sobre el pasado reciente y ethos discursivo en Néstor Kirchner (Argentina, 2003-2007) y José Mujica (Uruguay, 2010-2015)", Revista Uruguaya de Ciencia Política, vol. 24, núm. 2, 2015, p. 135.

${ }^{32}$ Naciones Unidas, op. cit. p. 4. El subrayado es del autor.

${ }^{33}$ Idem.
} 
es el goce de lo privado, es la disponibilidad real de tiempo "libre" dedicado a seguir la propia voluntad. En los valores que enumera, "amor", "amistad", "aventura", "familia", en definitiva "solidaridad" en las "relaciones humanas", no hay vinculación alguna con lo político y el "tiempo libre" lo es, precisamente, cuando éste se despoja de las necesidades más inmediatas. Se observará que Mujica utiliza el subrayado y la mayúscula para este término, lo que indica la relevancia que le otorga al elemento tiempo; el argumento consiste, como se verá más adelante, en que el tiempo es un recurso escaso y malgastado en tiempo de trabajo empleado en la conservación y acumulación inútil, y no sustentable, de bienes materiales.

Libertad es, en definitiva, tiempo libre de obligaciones económicas. Este concepto de la libertad desafiada por la urgencia del consumo capitalista, que a su vez amenaza la propia existencia humana por imposibilidad práctica de generalización, tampoco encuentra respuesta en la política que debe, apoyándose en las ciencias y no en la lógica del mercado "[...] batallar para preparar un Mundo sin fronteras". ${ }^{34}$ Es aquí donde Mujica introduce una referencia a la tradición republicana, desagregada respecto a los problemas que plantea. Lo republicano se desenvuelve más como verificación de un deterioro que como la reivindicación de un camino posible, y para constatar que

[...] Las Repúblicas nacidas para afirmar que los hombres somos iguales, que nadie es más que nadie, que sus gobiernos deberían representar el bien común, la justicia y la equidad. Muchas veces se deforman y caen en el olvido de la gente corriente.

[...] Por reminiscencias feudales o por clasismo dominador o por la cultura consumista, las Repúblicas en sus direcciones adoptan un diario vivir "espléndido" y excluyente en los hechos del pueblo común que vive y sueña y que debería ser objeto central a servir. ${ }^{35}$

Esta valoración del resultado del proyecto republicano, se establece luego de una referencia a "El Todo", que define desde una perspectiva radicalmente sistémica como "la vida global del Sistema Tierra incluyendo la vida humana con todos los equilibrios frágiles que hace posible perpetuarnos". ${ }^{36}$ Es esta totalidad la que requiere una gobernanza global que trascienda las fronteras del Estado Nación.

En la audición radial del 17 de octubre de 2014, Mujica precisó su idea de libertad. Reconociéndose explícitamente en la tradición republicana, identificó el republicanismo con la democracia representativa y la regla de la mayoría que para él "[...] componen un factor cuasi religioso en materia de definición". ${ }^{37} \mathrm{Y}$ si la democracia supone las decisiones de la mayoría, el representante debe llevar un estilo de vida conforme con el estilo de vida mayoritario. De esta manera justifica su desacuerdo respecto a la condición de "presidente pobre" que se le ha atribuido. A eso se debe su sobriedad como desapego de lo material, que se expresa en la necesaria identificación con el estilo de vida de las mayorías en una democracia: "[...] nos han hecho fama de presidente pobre y cuestiones por el estilo. No aceptamos, no somos pobres, para nosotros la definición de pobreza es la de los Aimara,

\footnotetext{
${ }^{34}$ Ibid., p. 5. El subrayado es del autor.

${ }^{35}$ Idem.

${ }^{36}$ Ibid., p. 7.

${ }^{37}$ Presidencia de la República, op. cit., p. 1.
} 
pobre es el que no tiene comunidad". 38 Pero por este derrotero la explicación vuelve a la idea de tiempo libre, que concibe como la ausencia de las restricciones que impone la necesidad de destinarlo a la conservación de los bienes materiales. El siguiente pasaje es significativo en este punto:

Por eso, no somos pobres, somos sobrios, con una sobriedad elegida y premeditada [...] porque es una opción de vida: vivir con poco, con lo justo, con lo necesario, para tener tiempo. Si tengo demasiado me tengo que perder muchísimo tiempo en atender esas cosas. Si tengo lo justo, vivo liviano de equipaje y me queda la mayor cantidad de tiempo posible para hacer esas cosas que a mí me motivan. ${ }^{39}$

Puesto que su idea de libertad está ligada a la expresión de la propia voluntad, considera que es el resultado de la consecución de las preferencias individuales, cualesquiera que sean, y eso lo conduce a establecer una distinción entre la "libertad individual" y la "libertad colectiva", esto es, política:

Otro puede sentir motivaciones por otras cosas y gastará el tiempo de su vida en lo que más le guste, ese es el margen de libertad individual que nos queda arriba del planeta. Después está la otra, la libertad en el sentido colectivo, pero hay una libertad individual que significa tener tiempo de la vida. ${ }^{40}$

En esta síntesis, la idea de libertad que construye, y que está en la justificación de su estilo de vida, es la libertad individual, una libertad destinada al tiempo libre para la satisfacción de las inclinaciones individuales. Por otro lado, si bien invoca el republicanismo, lo hace vinculándolo con la regla de la mayoría y la democracia representativa, al tiempo que observa cierto deterioro tanto del ideal como del proyecto político republicano. La sobriedad, el "vivir con poco", es una elección que responde a la forma de vida de las mayorías, pero es una sobriedad práctica subordinada al empleo del tiempo en la satisfacción de las inclinaciones individuales, que pueden ser políticas, espirituales, sociales, e incluso materiales aun cuando el consumo de masas es incompatible con la sustentabilidad del propio sistema.

Esta concepción es taxativamente liberal. Sin embargo, contradice la auto identificación de Mujica como tributario de la tradición republicana, tanto como las reservas que históricamente ha mantenido la izquierda política sobre las concepciones liberales.

\section{La libertad liberal}

Liberalismo y republicanismo son las dos tradiciones políticas rivales de la modernidad; mientras la segunda ha puesto al ejercicio de la ciudadanía al servicio de la conformación de una voluntad pública, para la primera los ciudadanos son ante todo individuos cuya

\footnotetext{
${ }^{38}$ Idem.

${ }^{39}$ Idem.

${ }^{40}$ Idem.
} 
libertad no colectiva sino individual, es necesario garantizar. ${ }^{41}$ Esto significa que cada una le atribuye a la palabra "libertad" significados difíciles de conciliar, y que solo nominalmente la libertad adquiere equivalencia en ambas tradiciones. De modo que la libertad liberal y la libertad republicana, conforman ideas contrapuestas sobre la libertad, que corresponden respectivamente a la diferencia entre libertad negativa y libertad positiva que ha definido Isaiah Berlin no como el resultado de "[...] dos interpretaciones distintas de un único concepto, sino de dos actitudes profundamente distintas e irreconciliables respecto a los fines de la vida". ${ }^{2}$ Mientras la libertad positiva implica "autogobierno", "autodeterminación", "autonomía", ausencia de un poder externo para afirmar el propio poder, la libertad negativa es la ausencia de impedimentos y limitaciones, o sea una libertad "negativa" porque se realiza en la negación de las restricciones a la libertad; en cambio la libertad "positiva" se trata de una afirmación respecto a la forma que adopta un poder propio, no externo al cuerpo político, o como establece Quentin Skinner, "de acuerdo con los teóricos republicanos, la libertad humana no solo se ve suprimida por actos de interferencia, sino también -y más fundamentalmente- por la presencia de un poder arbitrario". ${ }^{43}$ Con esta distinción los "fines de la vida" se ponen de manifiesto en palabras de Berlin: "los primeros querían limitar la autoridad en cuanto tal. Los últimos quieren que pase a sus manos. Esta es la cuestión cardinal". ${ }^{44}$ En suma, para el republicanismo la libertad se genera a partir de la asociación política, de la conformación de una comunidad política que se define autónoma; para los liberales, en cambio, la libertad es prepolítica, preexiste a la comunidad como libertad natural.

De este modo, el elemento clave para la determinar el sentido republicano o liberal de un discurso radica en la distinción que Cruz Prados le atribuye a la asignación, instrumental o constitutiva, de lo político en una u otra tradición: "frente a la concepción instrumentalista de lo político, propia del liberalismo, el republicanismo presenta una concepción - digámoslo así- constitutiva de lo político". ${ }^{45}$ De lo que se sigue que determinar, en el discurso de Mujica, si la libertad es el resultado de lo político, o si por el contrario la política es un instrumento para garantizar la libertad individual, adquiere especial relevancia. Puesto que la "libertad" se vincula de alguna manera con la "sobriedad", es necesario tratar conjuntamente ambos términos.

La sobriedad se explica en su discurso como resultado de dos elementos. En primer lugar, su correspondencia con la forma de vida de las mayorías, y en segundo lugar como requisito para la disposición de tiempo libre. El primero de ellos remite a la representación, y es una de las condiciones típicamente roussonianas para la democracia: "[...] poco o ningún lujo; pues o bien el lujo es el efecto de las riquezas, o las vuelve necesarias. [...] He aquí por qué un autor célebre ha establecido la virtud como principio de la república". ${ }^{46}$ Pero en el discurso de Mujica, la libertad no llega a concebirse como libertad positiva, esto

\footnotetext{
${ }^{41}$ Susana Villavicencio, "La (im) posible república”, Boron, Atilio (comp.), Filosofía Política Contemporánea. Controversias sobre civilización, imperio y ciudadanía, Buenos Aires, Clacso, 2003 , p. 83.

${ }^{42}$ Isaiah Berlin, "Dos conceptos de libertad", Sobre la libertad, Madrid, Alianza Editorial, 2012, p. 249.

${ }^{43}$ Quentin Skinner, Hobbes y la libertad republicana, Buenos Aires, Prometeo, 2010, p. 169.

${ }^{44}$ Berlin, op. cit, p. 249.

45 Alfredo Cruz Prados, "Republicanismo y democracia liberal: dos conceptos de participación”, Anuario Filosófico XXXVI/1-2, 2003, p. 87

46 Jean Jacques Rousseau, El contrato social, Losada, Buenos Aires, p. 101.
} 
es, republicana, por cuanto el problema que intenta resolver no es el de la presencia de un poder externo sino el de las limitaciones a la libertad concebida individualmente. En el discurso de Mujica, ser libre significa tener tiempo libre, y la sobriedad es consistente con la libertad solo porque permite la disponibilidad de tiempo y no por su ajuste respecto a un modo de vida popular. Es por esta razón que rechaza la "fama de presidente pobre": precisamente porque su sobriedad es también instrumental, y no la expresión de una virtud cívica.

La "virtud" es una pieza clave de la tradición republicana. Si la libertad se entiende como "autogobierno", en la virtud está la garantía del éxito del proyecto republicano, en la medida que una ciudadanía activa, que se gobierna a sí misma, debe orientarse al interés general y abandonar la consecución de los intereses particulares. En una comunidad política autogobernada, "liberada" respecto de un poder externo, no hay lugar para el choque de intereses, sino para la búsqueda del bien común. Esto significa que la virtud y los valores cívicos republicanos son, como establece Gerardo Caetano "[...] soportes del ejercicio de una «ciudadanía activa» que no fuera meramente episódica o circunstancial en las instancias electorales, sino partícipe permanente de la vida pública" ${ }^{47}$ Para Helena Béjar, "la virtud es el ímpetu del ciudadano dispuesto a contribuir activamente en la construcción de una esfera pública autorrealizadora". ${ }^{48}$ De ahí que la "austeridad" sea una "virtud" fuertemente atractiva para la tradición republicana, y por lo tanto un ciudadano activo, comprometido con su comunidad, debe cultivar estos valores: "la ciudadanía como concepto ético, el patriotismo como valor supremo, la austeridad en la vida y en el porte $[\ldots] " .49$

Ninguna de estas ideas está presente en el discurso de Mujica. Ni la virtud de la participación activa en una comunidad de iguales, ni la virtud como desapego del interés particular. Mujica no es "pobre", o bien simplemente "sobrio" en el sentido "virtuoso" del republicanismo, sino porque esa sobriedad significa una descarga de los impedimentos que hacen posible ser libre. En tal sentido, la renuncia a lo material de Mujica no es "virtud republicana" sino una forma de reducir las restricciones a la libertad en su sentido estrictamente liberal. Su libertad no emerge de su pertenencia a un cuerpo político que se gobierna a sí mismo, sino del abandono de ciertas restricciones e impedimentos a la expresión de la voluntad individual.

\section{Los "liberalismos" y la izquierda política}

El liberalismo, como se ha establecido, se opone al republicanismo en la medida que ambas tradiciones conciben a la libertad de distinta manera. No obstante, cualquier llamado de atención sobre esta separación es mucho menos frecuente que la distinción entre liberalismo y socialismo. Norberto Bobbio ha verificado que tanto en el plano ideológico, como en el de los movimientos y las instituciones, esto es, de la acción política, así también como en el ámbito de las ciencias sociales, la dicotomía entre el liberalismo y el socialismo

\footnotetext{
${ }^{47}$ Gerardo Caetano, La república batlista, Montevideo, Ediciones de la Banda Oriental, 2011, p. 73.

${ }^{48}$ Helena Béjar, El corazón de la república. Avatares de la virtud política, Paidós, Barcelona, 2000, p. 16.

${ }^{49}$ Cruz Prados, op. cit., p. 88
} 
es permanente y ha sido largamente construida. ${ }^{50}$ En pocas palabras, el liberalismo no es una tradición especialmente defendida por la izquierda. De acuerdo con esta contingencia, el apego del discurso de José Mujica a la libertad liberal, sería o bien contradictorio con los presupuestos teóricos de la izquierda que se han esforzado por alejarse del liberalismo, o bien no sería un discurso liberal sino republicano, tal como expresamente lo declara.

Pero la relación del liberalismo con el socialismo, y por ende, con la izquierda política, no siempre ha sido de lejanía. También es posible rastrear la historia de la integración entre el socialismo y el liberalismo, y sobre todo la estrecha relación que alcanzan en la corriente, escasamente transitada, del socialismo liberal, sustentada en "la idea de que el socialismo no es la antítesis del liberalismo sino, en cierta manera, su continuación y cumplimiento". 51

Aun así, cualquier relación, ambigua o manifiesta, entre el liberalismo y las concepciones que han dominado en la izquierda, siempre ha sido percibida como contraria no solo a los principios que a menudo invoca, sino incluso al sentido común. Las experiencias socialistas del siglo $\mathrm{XX}$ no han sido, por cierto, liberales, ni las obras socialistas fundamentales pueden incluirse sin problemas en esta tradición. Esto determinó que la corriente del socialismo liberal fuera más teórica que práctica: “[ ...] hasta ahora señala Bobbio- ha quedado o como un ideal doctrinario abstracto, tan seductor en teoría como difícilmente traducible en instituciones [...]", ${ }^{52}$ lo que significa que no ha sido siquiera ensayado como proyecto político.

En este escenario, el socialismo liberal debió hallar la relación del socialismo con la libertad liberal acudiendo a la separación entre política y economía. De esta manera, el liberalismo puede expresarse en el ámbito de la política, la sociedad, la cultura, sin los componentes del liberalismo económico, sin un laissez-faire inconciliable con un proyecto de izquierda. Tal distinción no es, sin embargo, meramente teórica. Para Giovanni Sartori resulta claro que el "liberalismo" es un sistema político y no un sistema económico, por lo cual, presentarlos de forma indiferenciada contradice toda evidencia histórica. ${ }^{53}$

Es así como la clave para que la izquierda pueda reconciliarse con el liberalismo, radica en desbrozar el componente económico del pensamiento liberal, o sea, establecer con absoluta claridad la distinción entre el "liberalismo político" y el "liberalismo económico", incluso dejando a este último fuera de la tradición liberal, o más aún, atribuyéndole al liberalismo económico directamente una deriva antiliberal. El esfuerzo acuñó términos como "liberismo" o "librecambismo" para referirse a la libertad en el campo económico, la libertad de mercado. Y en esta perspectiva la separación es profunda, siguiendo a Michelangelo Bovero, puesto hay una contradicción insalvable entre la libertad en el plano económico y la libertad en el plano político y social: si la libertad en la economía fuera absoluta, si no se registraran límites a la libertad de mercado "[...] engulliría todo derecho de libertad y, en último término, se engulliría a sí misma. Por el contrario, los derechos de

\footnotetext{
${ }^{50}$ Norberto Bobbio, Teoría general de la política, Madrid, Trotta, 2009, p. 384.

51 Ibid., p. 392.

${ }^{52}$ Norberto Bobbio, Liberalismo y democracia, Buenos Aires, Fondo de Cultura Económica, 1989, p. 96.

${ }^{53}$ Giovanni Sartori, Elementos de teoría política, Madrid, Alianza Editorial, 2005. p. 139.
} 
libertad subsisten como tales sólo con la condición de que se proteja y garantice su «libertad $\mathrm{del}$ [frente al] mercado»". ${ }^{4}$

La subsunción de lo económico en lo social, y por lo tanto la identificación de cualquier limitación a la libertad de mercado con la restricción de todas las libertades, no es una perspectiva seguida particularmente por los liberales, sino fundamentalmente por sus detractores. Para un republicano como Félix Ovejero, "el contrato es el paradigma de la libertad liberal: la relación de intercambio, la relación en la que yo me comprometo a hacer A (realizar un trabajo, entregar un bien, pagar un dinero) a cambio de tu compromiso de hacer B". ${ }^{55}$ Pero desde la tradición liberal, con escasas excepciones -como lo es, ciertamente, el pensamiento de Friedrich Hayek, para quien "es muy discutible que exista acción alguna que pueda denominarse sólo acción económica [...]"56_, esta distinción es frecuente y ampliamente aceptada "[...] puesto que el liberalismo político nació mucho antes que el liberalismo económico, pudo funcionar sin laissez-faire, [y] también es plausible que pueda funcionar en el futuro sin laissez-faire". ${ }^{57}$ Karl Mannheim ha llegado incluso a una suerte de identidad entre liberalismo y anarquismo, para quien la idea liberal de la libertad "[...] no es, en muchos puntos, sino la aplicación precipitada de la idea anarquista acerca del surgimiento de la libertad y la autodisciplina espontánea a la sociedad de masas". ${ }^{58}$ Para Mannheim, anarquismo y liberalismo plantean la misma idea acerca de la libertad aunque conciban contextos diversos que implican proyectos no convergentes, pero se distinguen ambos de la libertad "plutocrática" concebida en el plano económico. ${ }^{59}$

De modo que no observar una contradicción entre una concepción atribuible a la izquierda y una concepción liberal, o bien el argumento en el sentido que las restricciones al "librecambismo" no afectan el despliegue de la libertad individual, sino que la garantizan, han sido suficientemente establecidos. En la misma línea, la no distinción entre el liberalismo económico y el liberalismo político, especialmente visible en la crítica al liberalismo, contribuyó a la construcción del liberalismo y el socialismo como dos sistemas económicos contrapuestos y enfrentados entre sí. En cambio, distinguirlos permite concebir una noción de libertad negativa en el plano político y social, compatible con un sistema económico que supone restricciones en este ámbito, precisamente porque estas restricciones son la garantía de continuidad y pervivencia de la libertad. Renunciar a esta distinción, o ignorarla, ha impedido a la izquierda, en general, redescubrir al liberalismo e integrarlo dentro de una corriente crítica del desarrollo capitalista actual y su ideología dominante.

En el discurso de Mujica se encuentran todos los ingredientes de la crítica al capitalismo junto con la preferencia por la libertad individual. La distinción entre libertad individual y libertad de mercado, está implícita. En su discurso, la libertad se consagra, incluso, fuera de las obligaciones que impone el consumo de masas. Es esta libertad la que

\footnotetext{
${ }^{54}$ Michelangelo Bovero, ¿Cuál libertad? Diccionario mínimo contra los falsos liberales, México, Océano, 2010, p. 45.

${ }^{55}$ Félix Ovejero, Incluso un pueblo de demonios: democracia, liberalismo, republicanismo, Madrid, Katz, 2008, p. 49.

${ }^{56}$ Friedrich Hayek, Los fundamentos de la libertad, Madrid, Unión Editorial, 2014, p. 62.

${ }^{57}$ Sartori, op. cit. p. 140.

${ }^{58}$ Karl Mannheim, Libertad, poder y planificación democrática, México, Fondo de Cultura Económica, 1960, p. 298.

59 Ibid. p. 299.
} 
se muestra amenazada, y es esta libertad la que puede interponer el límite al actual modelo de desarrollo que amenaza la propia supervivencia de la especie humana.

Pero el discurso de Mujica puede considerarse liberal siempre que se establezca la distinción entre liberalismo político y liberalismo económico, siempre que se comprenda a la libertad en el sistema político y social, no indiscutiblemente ligada al librecambismo, que en cambio representa un sistema económico. Para Mujica, la búsqueda de acumulación material en un mundo dominado por la masificación del consumo entra en contradicción con las mismas condiciones de desarrollo de la humanidad, y constituye un modelo de desarrollo contra el uso del tiempo libre, lugar donde ubica a la verdadera libertad.

\section{Discusión}

Hemos planteado un recorrido que pone de relieve la novedad en el discurso de Mujica, y el asiento de su extraordinaria difusión: el descubrimiento -o redescubrimiento- de la libertad individual o, si se quiere, de la libertad liberal, dentro de una crítica al modelo de desarrollo capitalista actual que significa no la consagración de la libertad sino, precisamente, la causa de su deterioro. La distinción entre liberalismo económico y político, implícita en la crítica a la sociedad de consumo, le ofrece a la orientación ecologista un contenido ideológico más allá de lo estrictamente relacionado con la conservación del medio ambiente, al contraponer la libertad individual a la libertad de mercado. El discurso de Mujica ha sugerido, además, el replanteo de una discusión teórica sobre la relación entre el liberalismo y el socialismo, entre la libertad individual y el ideal de "liberación" de los pueblos, como ausencia de un poder externo, que con mucha más frecuencia ha sido utilizado para invocar una noción de la libertad claramente ubicada a la izquierda del espectro de ideas.

En sus aspectos relacionados con el fundamento de su "sobriedad", esta centralidad de la libertad liberal excluye la posibilidad de una apología de su comportamiento en los términos de una virtud republicana derivada del ejercicio de la autonomía y el autocontrol. La sobriedad de Mujica no es virtuosa sino práctica, es la fórmula que hace posible destinar el tiempo no a las obligaciones, sino a la sola voluntad. La promesa igualitaria del republicanismo, en cambio, se presenta como un proyecto inconcluso, cuya resolución no está en volver a impulsarlo, en impugnar nuevamente un poder arbitrario, sino en profundizar la libertad individual alejándose de las restricciones que impone el mercado, espacio diferenciado donde sobreviene la libertad en la economía.

Este desplazamiento, coincide con la relación que estableció la corriente, puramente intelectual y francamente minoritaria, que llevó las ideas del liberalismo político al terreno de las representaciones de izquierda y evidenció la complementariedad entre el socialismo y el liberalismo, sustituyendo su mutua negación por una relación de simetría. El parentesco que Mujica le atribuye al anarquismo y al liberalismo, por más que el discurso acuda a los ecos de una igualdad republicana, se sustenta siempre en la concepción de una libertad como ausencia de restricciones, como la ampliación de la esfera de la libertad individual, conformada en la disposición de tiempo para la vida.

Esta verificación abre una dirección analítica poco frecuente. Hace posible indagar derroteros escasamente transitados en el plano de las ideas, cuya importancia está 
justificada por el éxito de una perspectiva de esa naturaleza. La celebración internacional de la figura de Mujica, del discurso sobre la libertad, con apoyo en una acción política que combinó "sobriedad" e iniciativas liberales, expresión de voluntad individual y espacios efectivamente ganados a la libertad, vuelve a reunir ideales, pragmatismo y acción, en un giro tan singular como obstinadamente coherente con la historia. La dimensión teórica y práctica de esta relación está en condiciones de replantear la relevancia que adquieren tradiciones a menudo soslayadas, pero aun así ligadas al pensamiento y a la identidad ideológica de la izquierda.

\section{Bibliografía}

Aldrighi, Clara, Memorias de Insurgencia. Historias de vida y militancia en el MLN-Tupamaros. 1965-1975, Montevideo, Ediciones de la Banda Oriental, 2009.

Béjar, Helena, El corazón de la república. Avatares de la virtud política, Barcelona, Paidós, 2000.

Berlin, Isaiah, Sobre la libertad, Madrid, Alianza Editorial, 2012.

Bobbio, Norberto, Liberalismo y democracia, Buenos Aires, Fondo de Cultura Económica, 1989.

Bobbio, Norberto, Teoría general de la política, Madrid, Trotta, 2009.

Bovero, Michelangelo, ¿Cuál libertad? Diccionario mínimo contra los falsos liberales. México, Océano, 2010.

Breton, Philippe; Le Breton, David, El silencio y la palabra contra los excesos de la comunicación, Nueva Visión, Buenos Aires, 2011.

Caetano, Gerardo, La república batllista, Montevideo, Ediciones de la Banda Oriental, 2011.

Cruz Prados, Alfredo, "Republicanismo y democracia liberal: dos conceptos de participación", Anuario Filosófico XXXVI/1-2, 2003, p. 83-110.

Danza, Andrés, Tulbovitz, Ernesto, Una oveja negra al poder. Confesiones e intimidades de Pepe Mujica, Montevideo, Sudamericana, 2017.

Garcé, Adolfo, "Uruguay 2009: de Tabaré Vázquez a José Mujica", Revista de Ciencia Política, vol. 30, núm. 2, Pontificia Universidad Católica de Chile, Santiago, 2010, pp. 499-535.

Garcé, Adolfo, 2011, "Ideologías políticas y adaptación partidaria: el caso del MLN-Tupamaros", Revista de Ciencia Política, V. 31, No 1, Santiago, 2011, p. 117-137.

Hayek, Friedrich, Los fundamentos de la libertad, Madrid, Unión Editorial, 2014.

Johnson, Niki; Sempol, Diego, "Igualdad de género y derechos de la diversidad sexual: avances y rezagos en el gobierno de Mujica", Bentancur, Nicolás; Busquets, José, (coomp.) 2016, El decenio progresista. Las políticas públicas de Vázquez a Mujica, Montevideo, Fin de Siglo - Instituto de Ciencia Política, UdelaR, 2016.

Labrousse, Alain, Una historia de los tupamaros. De Sendic a Mujica, Montevideo. Fin de Siglo Editorial, 2011.

Maingueneau, Dominique, Análisis de textos de comunicación, Buenos Aires, Nueva Visión, 2009. 
Mannheim, Karl, Libertad, poder y planificación democrática, México, Fondo de Cultura Económica, 1960.

Montero, Ana Soledad, "El joven militante y el viejo sabio. Relatos sobre el pasado reciente y ethos discursivo en Néstor Kirchner (Argentina, 2003-2007) y José Mujica (Uruguay, 2010-2015)", Revista Uruguaya de Ciencia Política, vol. 24, núm. 2, 2015, pp. 120-137.

Ovejero, Félix, Incluso un pueblo de demonios: democracia, liberalismo, republicanismo, Madrid, Katz, 2008.

Panizza, Francisco, "Las política del signo. Los códigos y símbolos de la épica tupamara", Cuadernos del Claeh, $\mathrm{N}^{\circ}$ 10, Montevideo, 1985, p. 5-28.

Real de Azúa, Carlos, Partidos, política y poder en el Uruguay (1971-Coyuntura y pronóstico), Montevideo, FHCE, Universidad de la República, 1988.

Real de Azúa, Carlos, Uruguay. ¿Una sociedad amortiguadora?, Montevideo, Ediciones de la Banda Oriental, 1984.

Rodríguez, Raúl; Vairo, Daniela, "Las claves del éxito de Mujica en las presidenciales uruguayas de 2009”, Revista Debates, Porto Alegre, v. 5, n. 2, 2011, p. 97-116.

Rousseau, Jean Jacques, El contrato social, Buenos Aires, Losada, 2003.

Sartori, Giovanni, Elementos de teoría política, Madrid, Alianza Editorial, 2005.

Skinner, Quentin, Hobbes y la libertad republicana, Buenos Aires, Prometeo. 2010.

Villavicencio, Susana. "La (im) posible república" en Boron, Atilio (comp.), Filosofía Política Contemporánea. Controversias sobre civilización, imperio y ciudadanía, Buenos Aires, Clacso, 2003. 